\title{
Towards the implementation of an integrated ecosystem fleet-based management of European fisheries
}

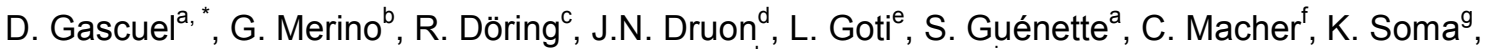 \\ M. Travers-Trolet ${ }^{h}$, S. Mackinsoni
}

\begin{abstract}
a Université Européenne de Bretagne, Pole Halieutique Agrocampus Ouest, UMR Ecologie et santé des écosystèmes, 65 Route de Saint Brieuc, CS 84215, 35042 Rennes Cedex, France

b Plymouth Marine Laboratory, Prospect Place, The Hoe, Plymouth PL1 3DH, United Kingdom c Johann Heinrich von Thünen Federal Research Institute, Institute of Sea Fisheries, Palmaille 9, 22767 Hamburg, Germany

d Joint Research Centre of the European Commission, IPSC, Maritime Affairs Unit, Via Fermi 1, TP 051,21027 Ispra, Italy

e Neike-Tecnalia, Basque Institute for Agricultural Research and Development, Campus Agroalimentario de Arkaute. Apto 46. E-01080 Vitoria-Gasteiz, Spain

f IFREMER Département d'Economie Maritime, UMR Amure, Centre de Brest, BP 70, 29280 Plouzané, France

g LEI-Wageningen UR, Alexanderveld 5, Postbus 29, 2502 LS Den Haag, Netherlands

h IFREMER Laboratoire Ressources Halieutiques, 150 Quai Gambetta, BP 699, 62321 Boulogne-sur-Mer, France

' CEFAS, Pakefield Road, NR33 OHT, Lowestoft, United Kingdom
\end{abstract}

*: Corresponding author : Didier Gascuel, email address : Didier.Gascuel@agrocampus-ouest.fr

\begin{abstract}
:
Using the Celtic Sea and the North Sea as case studies, the fleet-based approach is shown to be the pathway to implement an effective ecosystem approach to fisheries management (EAFM) in European seas. First, a diagnostic on the health of each ecosystem is proposed based on the reconstruction of long time-series of catch, the analysis of mean indicators or stocks trajectories derived from ICES stock assessment results, and the analysis of ecosystem indicators. Then, a fleet-based synthesis is presented using indicators of both the ecological impact and the economic performances of the major fleets operating within each ecosystem. In particular, assessment diagrams show whether each fleet segment, on average, sustainably exploits the stocks. Although results are preliminary due to the poor quality of available data, the analysis shows that simple indicators can be estimated and clearly highlight contrasts between fleet segments. Such an approach contributes to the evolution from a stock-based to a fleet-based management, which reflects the ecological, economical and social pillars of the sustainable development of fisheries.
\end{abstract}

\section{Highlights}

- The fleet-based approach is shown to be a pathway to implement an effective EAFM in Europe. Using the Celtic Sea and the North Sea as case studies, a diagnosis on the ecosystem health is proposed. Indicators are estimated to assess both the economic and ecological performances of the major fleets. Although results are preliminary, indicators highlight strong contrasts between fleet 
segments. This approach should contribute to develop an ecosystem-fleet-based management of fisheries.

Keywords : Ecosystem approach ; Economic performance ; Fisheries management ; Fleet ; Indicator ; Sustainable development

\section{Introduction}

The United Nations Food and Agriculture Organization (FAO) calls for the application of an "ecosystem approach" to fisheries management (EAFM) that provides for specific consideration of the interactions between fishing gears and marine ecosystems. EAFM takes into account that fisheries are embedded into the environment and cannot be managed in isolation [1]. It has to be considered as the application to the fishing sector of the sustainable development principles, combining ecological sustainability, economic viability and social fairness [2, 3].

Several tools have been developed with the aim of implementing EAFM, including ecosystem indicators [4-7] and modelling tools [8-10]. These developments have allowed integrated assessments on the state of exploitation [11-13] and dynamics of marine ecosystems [1416], as well as investigation of the impacts of different fleet segments in the marine environment [17]. Most of the tools developed to date have been devoted to investigations of the conservation of marine ecosystems or to the assessment of economic performances of multi-species fisheries [18-20]. Only few have been dedicated to investigate the trade-offs between ecosystem health and the economic or social performances of fishing fleets [1, 21]. In addition, despite the increasing number of frameworks and international agreements on EAFM, its practical implementation remains a challenge because it's difficult for managers to translate the concepts of EAFM into specific action plans at international, national or regional scales $[1,2]$. The interactions between the different components within an ecosystem have to be acknowledged, understood and quantified [22, 23].

Responsibilities for fisheries management in European seas are shared by neighboring countries through Exclusive Economic Zones (EEZ), and supported by the European Commission under the guidelines of the Common Fishery Policy (CFP). The CFP aims to promote responsible fishing in order to restore fish stocks, make fisheries economically efficient and provide high quality animal protein to more than half a million European consumers in 2020 [24]. Scientific advice on the stocks is undertaken by the International Council for the Exploration of the Sea (ICES) and the Scientific, Technical and Economic Committee for Fisheries (STECF) of the European Commission [25, 26]. ICES especially provides stock assessments and recommendations on the yearly stock by stock total allowable catches, and it also has the capabilities to provide a range of ecosystem indicators [27]. 
STECF recognizes that implementing the EAFM, including the development of associated ecological and bio-economic models, constitutes an important challenge and urgent need in Europe [28]. Adoption of an integrated ecosystem-based approach is particularly relevant in areas where multiple fleets and gears share target species, and it is necessary to assess the economic impact of proposed management measures on the affected fleets. An important explicit objective of the EAFM, which is defined by council regulation on the conservation and sustainable exploitation of fisheries resources [24], is to optimise economic activity while seeking to minimize the impact on relevant ecosystems. The urgency of reconciling consistency in the ecological-economic data sources required for operational support for EAFM is recognized by STECF [28].

This work aims to define a general analytical framework and verify data availability to effectively implement EAFM in European waters, taking consideration of conservation and economic goals. As a demonstration of the feasibility of the approach, two ecosystems were considered: the North Sea and the Celtic Sea. The North Sea (NS) is one of the most and best studied fishing areas in Europe. It has been mostly exploited by Danish, Norwegian, British, Dutch, Swedish and French fleets since 1950s [12]. Fisheries in the Celtic Sea (CS) have developed more recently, at a time when good fishery monitoring and survey programs were in place [29]. Analyses of trends in total landings suggests that Celtic Sea stocks are overexploited [30, 31], supporting calls for further development of data integration [32].

In both areas, the pathways to reconcile an effective EAFM with a fleet segment based management were investigated. To do so: (i) ICES catch by species time series were examined, (ii) estimates of stock status and ecosystem exploitation state trends were provided, (iii) a synthesis of fleet-based economic performance was elaborated, (iv) the dependency of the stocks and fleet segments on the Celtic and North Seas was investigated and (v) a first set of simple indicators of fleet segment ecological sustainability was proposed. Using these different analyses, we demonstrate that fleet-based management recommendations could be delivered to support an EAFM in the EU.

\section{Material and methods}

This research focuses on the Celtic Sea (CS) and North Sea (NS) fisheries used as case studies (Fig. 1). First, the ICES Statlant database was used to examine long term trends of landings of fish and shellfish. The spatial resolution of the ICES database allows landings to be assigned to ICES divisions (from 1950) and subdivisions (from 1973), but not to fleet segments. In this first approach, NS landings refer to division IV (subdivisions IVa-c), while the Celtic Sea includes subdivisions VIIe-k. According to 
both the surface and landings ratios of subdivisions VIId and VIIe (respectively eastern and western English Channel), 64\% of English Channel landings were assigned to the Celtic Sea.

The proportion of assessed stocks, based on the ratio of landings from assessed stocks over total landings, was used as an indicator of the awareness on the state of the ecosystem. Four time series of indices were computed to provide a synthetic overview of the trajectories of exploitation of all assessed stocks of the studied ecosystems: total landings (Y), spawning stock biomass (SSB), mean fishing mortality (mean F), and recruitment index in year $y\left(\mathrm{R}_{\mathrm{y}} / \mathrm{R}_{\text {average }}\right.$ ) (with $\mathrm{R}_{\text {average }}=\mathrm{R}_{1967-2008}$ for the NS, and $\mathrm{R}_{1972-2008}$ for the CS). Each indicator was aggregated over assessed species and used as multiple-stock indicators. Mean F and recruitment indices were averaged across the selected species while catch and SSB were summed. Not all stock assessments were available for the same periods, and as a consequence, alternative combinations of stocks and periods were compared to identify changes in trajectories, but a limited set of two combinations were selected to best represent each ecosystem (Table $1)$.

The current status of each assessed stock was summarized by comparing the biomass (B) and fishing mortality $(\mathrm{F})$ of the most recent assessment to the precautionary $\left(\mathrm{B}_{\mathrm{pa}}\right.$ and $\left.\mathrm{F}_{\mathrm{pa}}\right)$ and the $\mathrm{F}_{0.1}$ reference $\left(\mathrm{B}_{0.1}\right.$ and $\mathrm{F}_{0.1}$ ) points defined by ICES working groups. The latter two, based on a yield per recruit model, are commonly used to define the limit of full exploitation and considered here as a proxy for $\mathrm{F}_{\mathrm{MSY}}$ and $\mathrm{B}_{\mathrm{MSY}}$ respectively (see discussion). The synoptic method developed by Garcia and de Leiva Moreno [33] was used to normalize current $F$ and $B$ values. According to this method, the normalized $F$ is $F^{*}=\left(F_{\text {current }}-\right.$ $\left.\mathrm{F}_{0.1}\right) /\left(\mathrm{F}_{\mathrm{pa}}-\mathrm{F}_{0.1}\right)$ and $\mathrm{B}^{*}=\left(\mathrm{B}_{\text {current }}-\mathrm{B}_{\mathrm{pa}}\right) /\left(\mathrm{B}_{0.1}-\mathrm{B}_{\mathrm{pa}}\right)$. Furthermore, ecosystem indicators are computed by averaging $\mathrm{F}^{*}$ and $\mathrm{B}^{*}$ values of assessed stocks during the study period. These average trends present the status of the exploited part of the ecosystem compared to reference points.

In the Celtic Sea case study, two simple ecosystem indicators were estimated using landings from the ICES Statlant database and parameters from Fishbase (asymptotic lengths and mean trophic level per species):

. The mean trophic level of the landings [34] for year $y$ was computed as:

$$
T L_{y}=\sum_{i}\left(T L_{i} \cdot Y_{i y}\right) / \sum_{i} Y_{i y}
$$

where $Y_{i y}$ is the landings (yield) of year $y$ for species or group $i$, and $T L_{i}$ is the trophic level of species or group $i$.

. The mean asymptotic length of year $y$ of landings was estimated similarly from species asymptotic lengths $\left(L_{\infty}\right)$ as: 
$L \infty_{y}=\sum_{i}\left(L \infty_{i} \cdot Y_{i y}\right) / \sum_{i} Y_{i y}$

For the North Sea, three ecosystem indicators were available from the Indiseas project $[6,16]$, and thus used in the current analysis: the mean trophic level of the landings, the mean length of landed fish and the proportion (in weight) of predators (conventionally defined as species with $\mathrm{TL}<3.5$ ).

Next, a fleet-based synthesis was developed based upon the fleet segmentation defined by the European Union Data Collection Framework (DCF) of the CFP. To do so, standard indicators of the economic performance of fleet segments were reviewed on the basis of the 2010 Annual Economic Report (AER) on the European Fishing Fleet [35]. The impact of each fleet upon NS and CS stocks and their economic dependency on both ecosystems were investigated. Only the fleets that represented more than $2 \%$ of total landing value in (2006-2008) were selected. Additionally, following expert knowledge, two important French fleets operating in subdivision VII were added for the CS despite their data not being disaggregated in subareas. Non-EU fleets were ignored for this analysis.

For each fleet segment from NS and CS, the ratio of the landing value in the ecosystem to their total revenues was used as an index of their dependency on each ecosystem. The contribution of each fleet segment to the total fishing mortality was calculated as an indicator of their impact on the most important fish stocks. The sum of all the partial fishing mortalities was used as an index of the impact of each fleet segment on both ecosystems. Two sustainability indices were also calculated for each fleet segment: the average of the normalized fishing mortalities $\left(\mathrm{F}^{*}\right)$ for all the assessed stocks exploited by the fleet and the average of the normalized biomass $\left(\mathrm{B}^{*}\right)$ for all these stocks, both for 2008 data and using averages weighted by the values of landings per stock. By definition, the sustainability indices therefore allow assessing whether a fleet segment is economically dependent on stocks that globally are healthy or not in comparison with the reference points defined by ICES. Partial F and sustainability indicators were used to link fleets and stocks under the EAF perspective.

The appropriateness of EU collected data on the ecosystem and economic aspects was also discussed, with a particular focus on the CS and NS ecosystems, to identify potential improvements in data collection systems and model developments with the aim of reducing uncertainty of the EAFM approach. 


\section{Results}

\subsection{Ecological indicators and ecosystem diagnosis}

Landings of most representative species for the Celtic and North Seas (Fig. 2a and b) indicate that pelagic species are dominant in both ecosystems with Atlantic mackerel and Atlantic horse mackerel as the most caught species in the CS and sandeels and herring in the NS. In both cases, total landings declined consistently since 1995 .

In the CS, the proportion of landings from assessed stocks increased up to $70 \%$ by 1993 and then started to decline. ICES working groups assessed fewer stocks during the recent years due to insufficient data reporting or high uncertainty in several biological parameters (such as growth). Consequently, only $30 \%$ of the 2008 landings are from stocks that were assessed, while assessment is missing important stocks such as cod, hake or monkfish. In comparison, the coverage of assessments is high in the NS. In the early 1980s, NS sandeel (30\% of landings) became an assessed stock which makes the proportion of landings from assessed stocks reach almost 90\%. The English Channel sole, the horse mackerel and the Norway pout were evaluated starting in 1982 as well. Since 2007 however, sprat has not been evaluated, and the assessed proportion decreased to $78 \%$.

The synthesis of stocks, derived from aggregation of the ICES stock assessments, highlights some major changes that occurred in the exploitation of the two ecosystems (Fig. 2c and d). In the CS, the 4, 5 and 9-stock fishing mortality showed a slight increase in the 80s and 90s before significantly decreasing in the 2000s (Fig. 2c). Although both fishing mortality and landings decreased since 2000, the SSB index did not increase proportionally as a response. SSB remained relatively constant for the 4 and 5 -stock aggregations in the 80s, while the index for the 9-stock aggregation fluctuated more following the highly variable horse mackerel biomass. The stock recruitment indices varied widely and are characterized by several events of high recruitment (two times the average) caused by horse mackerel in 1983, cod in 1987 and whiting in 2008. Overall, recruitment has declined since 1992 for the three stock assemblages considered.

In the NS, the mean fishing mortality fluctuated at high levels and without clear trend during the 70s and early 80s (Fig 1d). However since 1986, the 6 and 14-stock F indices exhibit a similar pattern indicating that the fishing mortality has decreased by a factor of 2 in the NS. The 6-stock SSB oscillates and a long term pattern cannot be clearly identified. After a relatively stable decade, the 14-stock SSB seems to increase since 1995 from 10 to 14 Mt. The 6-stock SSB display a similar pattern, but its decrease in the 
very last years prevents the conclusion of an increasing trend. Globally, the NS commercial fish community may have started to recover for the last 15 years, maybe as a consequence of $\mathrm{F}$ reduction. Despite some variability, the recruitment index has been relatively constant until the late 90s. Since 2002, global recruitment has consistently decreased and the last records are the lowest in the time series, which could explain why SSB did not show a more clear recovery after the reduction in F.

Whether the relative biomass or the levels of fishing mortality are taken into account, both indicators show that most assessed stocks in the CS are overexploited (Fig. 3a). Plaice in VIIfg, cod and mackerel are below precautionary biomass levels. Whiting, plaice in VIIe, megrim and monkfish biomass remain above precautionary levels but are exploited at higher than the precautionary fishing mortality F. Hake and sole are both above precautionary biomass levels and below precautionary F. However, both are far from the $\mathrm{F}_{0.1}$ reference points. The estimated mean trajectories of $\mathrm{B}^{*}$ and $\mathrm{F}^{*}$ in the CS show that the 2stock group (cod and sole) was already overexploited $\left(\mathrm{F}>\mathrm{F}_{0.1}\right)$ and close to the precautionary level since the early 1970s; its biomass declined below precautionary levels at the end of the time series. Although the 5-stock trajectory (previous species plus plaice, hake and whiting) stays above $\mathrm{B}_{\mathrm{pa}}$, fishing mortality remained above $\mathrm{F}_{\mathrm{pa}}$ levels except for the last year considered. In summary, CS stocks are globally unsustainably exploited with 7 stocks (among 9) failing to meet precautionary objectives. Although fishing pressure seems to have decreased in the last 10 years, it remains significantly higher than $F_{0.1}$ for all stocks. The total biomass of these stocks remains low, at very close to precautionary levels.

The current status of NS stocks (Fig. 3b) shows that cod is outside precautionary limits both for biomass and fishing mortality. Herring is at very low biomass levels. Mackerel and sole in VIId stocks are exploited above $\mathrm{F}_{\mathrm{pa}}$. On the other hand, blue whiting's biomass is above the $\mathrm{B}_{0.1}$ limit although fishing mortality is close to precautionary levels. Note that only less than $3 \%$ of this stock is present in the North Sea. Temporal trajectories show a sequential degradation of the exploited part of the ecosystem over the years with $\mathrm{F}^{*}$ and $\mathrm{B}^{*}$ values being for a long period in the "high risk" area. The longer time series involving the stocks of cod, haddock, herring, plaice in IVa-c, saithe and sole in IVa-c starts in 1967 with biomass slightly above $\mathrm{B}_{\mathrm{pa}}$ and fishing mortality between $\mathrm{F}_{0.1}$ and $\mathrm{F}_{\mathrm{pa}}$ and ends in 2008 at biomass below precautionary levels and fishing mortality within the precautionary limit. The second series, comprising the previous stocks and mackerel, sole in VIId and sole in IIIa ends in 2008 with a fishing mortality above precautionary level and a biomass within the precautionary limit. Both series show a significant rise of the exploitation in the 80s and early 90s and alleviation in the last decade. However, the mean fishing mortality remains very high and the current status of the exploited ecosystem appears to be far from recovery. 
Landing-based indicators reflect changes both occurring in the ecosystem and the fishing strategies (Fig. $3 \mathrm{c}$ and $3 \mathrm{~d}$ ). The mean trophic level of landings in the CS shows a clear decrease by about 0.3 since the end of the 80s. This follows the decrease in the landing of cod or whiting-alike species and the increase in mollusc and crustacean landings. On the contrary, no clear trend is observed in the landings mean asymptotic length calculated for all fish and for demersal species only. Fluctuations in the all-species trajectory are due to horse mackerel landings, while for demersal species, the indicator remains stable within a $10 \mathrm{~cm}$ variation. For the NS, mean trophic level of catch and mean length of fishes have decreased significantly since their maxima in 1972 and 1983 respectively. Proportion of predators in landings has remained stable around $50 \%$ since 1983 (except for an abrupt decrease in 1987).

\subsection{Fleet-Based synthesis}

Twelve and ten fleets were selected in the CS and NS respectively for the fleet based analysis (Table 2a and $2 \mathrm{~b}$ ). The gross value added, operating cash flow, profit/loss and direct subsidies were used as indicators of economic performance of all fleets (Fig. 4). In the Celtic Sea, Dutch pelagic trawl (>40m), French demersal trawl (12-18 and 18-24m), British demersal trawl (18-24m) and British pots and traps fleets appears to generate the highest gross value added (GVA). In term of profitability, British fleets (demersal trawl or pots and traps) exhibit large operating cash flow and positive profits, while Dutch pelagic trawlers $(>40 \mathrm{~m})$ and even more French demersal trawlers $(18-24 \mathrm{~m})$ appear to be the less profitable fleets, exhibiting negative profits. It is important to note that this French fleet shows the most important deficit in spite of being subsidized.

For the North Sea, British purse seiners over 40m show the highest gross value added operating cash flow (31 million Euros) and level of profits in 2008. Another important fleet segment in terms of GVA and operating cash flow is represented by the Danish pelagic trawlers over $40 \mathrm{~m}$, with the second highest level of profits (12 million Euros). In contrast, negative profits are registered for Dutch beam and pelagic trawlers over $40 \mathrm{~m}$. This is also the case for the Danish pelagic trawlers $(24-40 \mathrm{~m})$, this fleet segment being, on the other hand, the one benefitting from the highest amount of subsidies. Finally, the British demersal trawlers and the British vessels using pots and traps are the most important fleet segments in term of vessel numbers and employment, and exhibit intermediate values for all economic indicators considered.

The fleets' impact on assessed fish stocks was investigated using partial fishing mortalities (Fig. 5a and 5b). In the CS, French demersal trawlers are the main responsible for whiting, cod and monkfish 
exploitation. This fleet has the highest direct impact on the exploited fraction of the CS ecosystem. Belgian beam trawlers which target sole and plaice are in second position in terms of direct impact on the CS assessed stocks. The other important fleet segments are the Irish demersal and British beam trawlers. From that figure, British pot and traps and Dutch pelagic trawlers of more than 40m appear to have very low impact on the CS fish stocks, but they are also mainly exploiting resources that are either not assessed by ICES or located outside of the CS.

The fleet segments which induce the highest fishing mortality in the North Sea (Fig. 5b) are the Danish pelagic trawlers (>40m) mostly harvesting sandeel, the British demersal trawlers (18-24 and 24-40m) mainly targeting whiting and haddock, and the Dutch beam trawlers catching sole and plaice.

The fleet dependencies on ecosystems (CS and NS) were estimated using the fraction of landings in value by fleet and by species (including the non-assessed landings, Fig. $5 \mathrm{c}$ and $5 \mathrm{~d}$ ). For instance, French (12-24m) dredges and Irish demersal trawlers (12-18 and 18-24m) take their revenues almost exclusively from the CS. British and Irish beam trawlers (24-40m) also depends for more than $80 \%$ from the CS. Regarding the North Sea, all selected fleet segments are highly dependent on this ecosystem. The revenues of Dutch beam trawlers (18-24 and >40m, mainly targeting crangon and sole respectively) and British demersal trawlers (18-24 and 24-40m, making the most profits from whiting and haddock) depend for $80 \%$ or more from the North Sea.

The sustainability index for the fleets operating in the CS and NS (Fig. 5e and 5f) allow identification of the fleet segments that are exploiting stocks in poor condition. In the CS, Dutch pelagic trawlers $(>40 \mathrm{~m})$ are harvesting stocks that are, on average, below their precautionary biomass levels $\mathrm{B}_{\mathrm{pa}}$ and heavily overexploited $\left(\mathrm{F}>\mathrm{F}_{\mathrm{pa}}\right)$. Most of the analyzed fleets are fishing stocks subject to unsustainable harvest rates and out of biomass or fishing mortality precautionary levels. Only three of the selected fleet segments are operating stocks within precautionary limits: Belgian beam trawlers (24-40m, mainly exploiting plaice and sole), French dredgers (12-24m, mainly exploiting scallops in the Bay of Saint Brieux) and British pots and traps. None of the fleets operate within the $\mathrm{F}_{0.1}$ limit level in the CS.

In the North Sea, six of the ten selected fleets are operating outside precautionary limits. For three fleets (UK purse seiner $>40 \mathrm{~m}$, NLD pelagic trawl $>40 \mathrm{~m}$, UK pots and traps $<10 \mathrm{~m}$ ), both $\mathrm{F}$ and $\mathrm{B}$ precautionary levels are not satisfied. Note that the British pots and traps fleet targets many species which are not assessed by ICES. The only selected fleet segments that are exploiting species within precautionary limits are the beam trawlers targeting sole and plaice and the large Danish pelagic trawlers. 
Finally, the sustainability of fleets' activity is plotted against their economic dependency on the ecosystem (Fig. 6a and 6b). British demersal trawlers (24-40m) are exploiting CS stocks at unsustainable rates but the revenue of that fleet is relatively independent from that area. In contrast, Irish beam trawlers (24-40m) also exploit that resource at unsustainable rates but are highly dependent on the CS ecosystem. This implies that the British demersal trawlers (24-40m) activity in the CS could more easily be restricted in support of measures for the ecosystem protection compared with the Irish beam trawlers.

As a conclusion on the fleet synthesis, differences between fleet segments can be identified at ecosystem level as some fleets segments exhibit poor economic performance and high ecological impacts while others may be considered as more virtuous. For instance, based on available data, the French demersal trawlers $(12-24 \mathrm{~m})$ operating in the CS seems to be characterized by: negative profits although benefitting from subsidies (Fig. 4), a high impact on stocks, and a poor sustainability index. The same applies to the British demersal trawlers except for their positive profits. On the other side, British pot and traps fisheries in CS seem to be profitable and their ecological impact on assessed stocks appeared to be within precautionary limits. Similarly, large contrasts exist between fleet segments operating in the NS ecosystem. Several (e.g. the Danish pelagic trawlers 24-40m) appear to be largely subsidized while characterized by low economic performances and a high impact on stocks in poor condition. Other fleet segments (e.g. Dutch beam trawlers $(>40 \mathrm{~m}$ ) appear to operate within the conditions of sustainable fisheries, although none operate at a level above $\mathrm{F}_{0.1}$.

Because of the lack of data (mainly linked to the fact that some countries did not fill the 2010 database for the European annual economic report at the right level of disaggregation), these results have to be considered as preliminary and cautiously interpreted. Nevertheless the key objective was to show that, from the methodological point of view, simple indicators can be estimated to assess both the economic and ecological performances of the various fleets.

\section{Discussion}

\section{- Building a stock-based diagnosis at the scale of the ecosystem}

The presented stocks' synthesis appears to be a key element of the EAFM to complement results based on single species assessments. Such synthesis at the ecosystem level provides an important overview on the best current estimates of the status of all the exploited and assessed stocks of the given ecosystem. 
Building progressively on the existing rigorous framework, we developed a synthesis using existing reference points $\mathrm{F}_{\mathrm{pa}}$ and $\mathrm{F}_{0.1}$ (and $\mathrm{B}_{\mathrm{pa}}$ and $\mathrm{B}_{0.1}$ ) so that the status of each stock is defined with reference to both the "old" precautionary reference values and the new reference values of maximum sustainable yield (MSY). Political commitments state that the new MSY-based objectives should be reached (for the fishing mortality) in 2015, thus the monitoring of trajectories for each individual assessed stock or as a whole will be of particular interest in the coming years. Following STECF advice [36], $\mathrm{F}_{0.1}$ was used as a proxy of $\mathrm{F}_{\mathrm{MSY}}$ since no direct estimates of $\mathrm{F}_{\mathrm{MSY}}$ are currently available for most stocks. This approach could be improved in the near future if appropriate estimates of $\mathrm{F}_{\mathrm{MSY}}$ become available. Because in the current exercise the purpose of the stock synthesis is to draw a general picture of the stocks' status at the scale of the ecosystem (and not for instance to estimate TAC per stock), coarse estimates (or proxies) of $\mathrm{F}_{\mathrm{MSY}}$ provide sufficient information.

In the EAFM perspective, a valuable stock synthesis requires that a large part of the exploited stocks, if not all of them, would be assessed. From that point of view, differences were observed not only between ecosystems but also changes over time. The proportion of landings coming from stocks that are assessed by ICES has decreased in the recent years, notably in the Celtic Sea (from 70 to $30 \%$ of total landings). This is due to a decrease in the number of stocks that ICES working groups are able to assess (mainly caused by the lack of data delivery by Member States, but also because of methodological issues not yet resolved, as it is the case for sprat in NS) and to an increase in landings of species which are not assessed (or assessed by national bodies).

This trend contrasts with as a requirement of the EAFM of assessing all resources exploited as targets. It should be admitted as a general ethical rule that the exploitation of a natural resource implies a scientific survey (if no assessment, then no fishing). Such assessments do not have to be provided on an annual basis and use the same full set of age-based methods. Various approaches based on surveys and/or models could be considered, depending on the species and fishery characteristics. As for non-targeted species, exhaustiveness is certainly not realistic, and a strategy has to be defined in order to assess a sufficient number of stocks to cover a large and consistent portion of the exploited part of the ecosystem. It should be a high priority for management and scientific bodies to define this strategy in all ecosystems, to build a database of assessments, and to gather the necessary data for all exploited stocks.

- On the Celtic Sea and North Sea preliminary results 
The Celtic Sea has been intensively exploited for decades [30] and total landings have declined rapidly over the last 15 or 20 years. Although the fishing pressure has been reduced since the beginning of 2000s, it is still high for many stocks which remain in poor condition with biomass near the precautionary limits $\mathrm{B}_{\mathrm{pa}}$. For the last observed year, 6 among the 9 stocks assessed by ICES in this area were at levels outside of the limits defined by the precautionary approach and all of them were overexploited (with $\mathrm{F}>\mathrm{F}_{0.1}$ ). Regarding the North Sea, species such as herring and cod have been intensively exploited for centuries. Total landings peaked in the mid-70s before decreasing by more than a factor of 2 during the last three decades. From 1985, the mean fishing mortality has constantly decreased, accelerating the decrease observed in the total landings. At the same time the total spawning stock biomass seems to have increased (although it is not clear for the very last years), which suggests that a recovery of the resources may have began. Nevertheless, all the assessed stocks by ICES are still overexploited (with fishing mortalities above $\mathrm{F}_{0.1}$ ), $40 \%$ of them failing to meet the precautionary objectives. The conclusion from the stock synthesis in the NS is that the reduction of fishing mortality may have initiated the recovery of the North Sea major stocks, but has to continue or even be strengthened as the SSB displays no conclusive trend in the very last years.

To our knowledge, there is no previous study presenting estimates of the ecosystem indicators recommended by STECF for the Celtic Sea. As a first proxy, and for the two ecosystems, the mean trophic level of catches was calculated using available data. For both case studies a very significant decrease can be observed over the last 20 years indicative of the "fishing down the food web" phenomenon [34] or a "fishing through the food web" trend [37]. It should be noted that this decline in mean TL of the catch can also be ascribed to dedicated management actions targeted at systematically reducing the removal of larger higher trophic level species, such as cod. However, ecosystem indicators calculated by EU working groups or research program in the North Sea confirm that, in its current situation, this ecosystem is not exploited sustainably. While the fishing pressure appears to decrease, ecosystem indicators such as the conservation status or the size at maturation of exploited fish species seem to indicate that the ecosystem status is worsening. Only one indicator (proportion of large fish) seems to be improving in the NS [28, 38].

\section{- Building a fleet-based synthesis.}

The development of a fleet-based synthesis using indicators of both the ecological impact and economic performances of fleets operating in the ecosystem also appears to be a key step of EAFM. Here, a first attempt (and, as far as we know, a completely new approach) is presented to derive indicators of the impact of each fleet segment on the exploited resources of an ecosystem using stock assessment results. 
For that purpose the best knowledge issued from ICES assessments was used to characterize the fleet impact on the fishable fraction of the ecosystem. In that sense, this approach has to be considered part of the EAFM.

Due to the poor quality of available data (e.g. no data at the appropriate level of aggregation for some member states), results presented here should be considered as very preliminary and thus cautiously interpreted. Nevertheless, from the methodological point of view the test was successful. Partial mortalities and sustainability indices allow the enhancement of significant differences between the various fleet segments operating in the ecosystem in term of global (and direct) impact on the fishable fraction of the ecosystem. Assessment diagrams, based on standardized fishing mortalities and biomass, show whether each fleet segment sustainably exploits stocks, compared to the $\mathrm{F}_{0.1}$ and $\mathrm{F}_{\mathrm{pa}}$ (or $\mathrm{B}_{0.1}$ and $\mathrm{B}_{\mathrm{pa}}$ ) targets. Obviously, this approach would be more powerful as the fraction of the total fleet landings included in the analysis approaches $100 \%$. This endorses the fact that from the EAFM point of view all resources exploited as targets should be taken into account in the assessment process.

Another limitation of the method is that following the DCF, the economic performance by fleet is only available with reference to the three large marine areas: the Baltic Sea, the Atlantic waters and the Mediterranean Sea [39]. Moreover, there is no existing methodology to allocate these economic performances among different ecosystems. The proportion of the total value of landings of a fleet was used as an indicator of the dependency of the fleet on the ecosystem and a proxy of the time spent in the ecosystem. When this indicator is high for a fleet segment (as it is the case for most segments in the North Sea), it can be considered as a satisfactory proxy to use economic indicators available in the DCF, even if they are not disaggregated by region or ecosystem. When dependency of the fleet to the ecosystem is low, further analyses are required to define a method for disaggregating economic performance at the ecosystem level. More generally, data availability at the regional level is a key factor and implementing EAFM in European Seas should probably lead to an in-depth revision of the DCF. Tradeoffs between ecological impact and economic performances should be provided at least on an ecosystem basis (i.e. at the scale of a regional sea). Therefore economic analyses at the ecosystem level are clearly required and a revised DCF should consider the ecosystem spatial reference for collecting the data.

A more important limitation of the presented approach is that only direct impacts on exploited species were considered. Neither impacts on seabed habitat (e.g. due to trawling and dredging), nor indirect impact to other ecosystem compartments through the food web are addressed. This aspect entails more 
developments. The impact on seabed habitat requires devoted studies while the impacts on other foodweb components are commonly addressed in ecosystem models. These indirect impacts will need to be included in the frame of a more complete assessment of ecological impact of each fleet segment, tacking into account the new indicators of the marine good environmental status, as defined by the Marine strategy directive framework [40]. In addition, further integrated approaches, such as LCA (Life Cycle Analyses) [41, 42], should also be investigated in order to analyse the environmental impact of various fishing practices.

\section{- Towards a fleet-based management}

Even if our results are preliminary, they clearly highlight differences between fleet segments operating in the Celtic Sea and the North Sea, for both their economic performance and ecological impact. Although more appropriate data collection systems are highly recommended [43], the economic indicators from the annual economic report show that several fleet segments are more subsidized than others [35]. Some account for negative profits and have severe impacts on the ecosystem, while others are more efficient in their economic balance and have moderate ecological effects. This economic and ecological analysis by fleet is a step forward to a fleet-based management within the ecosystem. It strengthens the fact that subsidies do not resolve the long-term economic problems of the fishing industry and, furthermore, they are increasing the ecosystem degradation $[44,45]$.

We also presented a preliminary attempt to identify tradeoffs between the ecological impact and economic performances of the selected fleet segments crossing the sustainability index with the economic dependency to the ecosystem. Other tradeoffs should obviously be tested and analysed, crossing for instance cash flow or profits or subsidies (...) with fishing-induced mortality or sustainability indices. This could especially contribute to determine which indicators are the most suitable to rationally identify tradeoffs when implementing EAFM.

Although the method still needs improvements, it can already be concluded that environmental assessments (including additional indicators on habitats, social aspects, etc.) will likely highlight major differences in fleet ecological impacts and economic or social performances. Some fleet segments will likely exhibit both strong ecological impacts and poor economic or social performances, while others will appear to have more virtuous activity in all aspects. For some other fleet segments the analysis will be more complex and a global assessment will have to integrate a compromise between ecological, social and economic indicators. Note that such a compromise generally occurs in the environmental impact assessment of all industrial activities. Fishing practices are no exception. 
For the management point of view, the next question will be: what to do with such assessments? The assessment of the ecosystem status could clearly be part of a framework used to determine which fleet segments would have to be reduced and which ones could be developed. Environmental assessments should also be used to guide management plans for fishing effort or to introduce positive or negative economic incentives in order to encourage fleets to improve their fishing practices. The payment for ecological services is quite common in agriculture to promote ecosystem preservation [46] and reduction of anthropogenic pressure [47]. However, this is not easily transferable to fisheries management. Current subsidies for environmental-friendly fishing gears are part of the European Fisheries Fund (EFF) but the overall use of such gear is often a risk for fishing companies in a context of strict economic competition where impacts on the ecosystem are not the priority.

\section{Conclusion}

This analysis shows that simple indicators can be estimated and used to assess both the economic and ecological performances of the various fleets operating within an ecosystem. Results should be strictly considered as a first and noticeably incomplete step. Nevertheless, it is an important one in the frame of EAFM as it links the stocks with the fleets (i.e. also State and Pressure in the PSR paradigm). Consequently, this work contributes to evolve from stock-based management to integrated fleet-based management of fisheries. In such an approach, the challenge is not to replace the stock by stock management which noticeably remains a necessity, but to develop an additional fleet-based management in order to enforce the ecological, economical and social pillars of the sustainable development of fisheries [1].

Our work using the North Sea and the Celtic Sea as case studies also confirms that such ecosystems represent the appropriate level (i) to draw synthesis on stock status and analyze trends in ecosystem indicators, (ii) to study in the same framework ecological impacts and economic performances of fleet segments and (iii) to analyze tradeoffs between the economy and ecology for a sound fleet-based management of fisheries. The size of these regional seas also appear to be a fair compromise for developing models devoted to scientific advice in both ecological and economic frames. The use of such an approach is also likely to improve the dialogue and the involvement of stakeholders (including fishermen representatives and especially within the RACs) as well as to build efficient integrated management plans. 
Finally, it has to be asserted that inputs from both ecological and economic perspectives are required. This work shows that ecosystem- and fisheries-based management approaches are not only complementary, but also structurally linked. We thus consider that creating a new organization of working groups devoted to scientific advice in the field of fish stocks, environment and economy on an ecosystem basis is required to properly support the implementation of EAFM and the sustainable management of European fisheries.

\section{References}

[1] Garcia S, Zerbi A, Aliaume C, et al. The Ecosystem Approach to Fisheries, FAO Fisheries Technical Paper No. 443, Rome, FAO. 2003, 71 pp.

[2] Garcia SM, Cochrane KL. Ecosystem approach to fisheries: A review of implementation guidelines. ICES Journal of Marine Science 2005; 62:311-318.

[3] Gascuel D, Bez N, Forest A, Guillotreau P, Laloé F, Lobry J, Mahévas S, Mesnil B, Rivot E, Rochette S, Trenkel V. A Future for marine Fisheries in Europe (Manifesto of the Association Française d'Halieumétrie). Fisheries Research 2011; 109:1-6.

[4] Shin YJ, Rochet M-J, Jennings S, et al.. Using size-based indicators to evaluate the ecosystem effects of fishing. ICES Journal of Marine Science 2005; 62:384-396.

[5] Cury P, Shannon L, Roux J-P, Daskalov G, Jarre A, Moloney C, Pauly D. Trophodynamic indicators for an ecosystem approach to fisheries. ICES Journal of Mar Science 2005; 62:430-442.

[6] Shin Y.S., Shannon L., Bundy A., Coll M., Aydin K., Bez N., BlanchardJ., Fatima Borges M. (de), Diallo I., Diaz E., HeymansJ., Hill L., Johannesen E., Jouffre D., Kifani S., Labrosse P., Link J., Mackinson S., Masski H., Möllmann C., Neira S., Ojaveer H., Abdallahi K.olM., Perry I., Thiao D., Yemane D., Cury P. Using indicators for evaluating, comparing, and communicating the ecological status of exploited marine ecosystems. 2. Setting the scene, ICES Journal of Marine Science 2010; 67: 692-716.

[7] Libralato S, Coll M, Tudela S, Palomera I, Pranovi F. Novel index for quantification of ecosystem effects of fishing as removal of secondary production. Marine Ecology Progress Series 2008; 355:107-129.

[8] Pauly D, Christensen V, Walters C. Ecopath, Ecosim, and Ecospace as tools for evaluating ecosystem impact of fisheries. ICES Journal of Marine Science 2000; 57:697-706.

[9] Fulton E. Approached to end-to-end ecosystem models. Journal of Marine Systems 2010; 81:171-183.

[10] Gascuel D, Guénette S, Pauly D. The trophic-level based ecosystem modelling approach: Theoretical overview and practical uses. ICES Journal of Marine Sciences 2011; 68:1403-1416.

[11] Coll M, Libralato S, Tudela S, Palomera I, Pranovi F. Ecosystem Overfishing in the Ocean. PLoS ONE3. 2008; e3881.

[12] Mackinson S, Daskalov G. An ecosystem model of the North Sea to support an ecosystem approach to fisheries management: description and parameterisation, Sci. Ser. Tech Rep., Lowestoft. 2007, 196 pp.

[13] Araújo J. Exploring fisheries strategies for the western English Channel using an ecosystem model. Ecological Modelling 2008; 210:465-477.

[14] Link J, Fulton E, Gamble R. The northeast US application of ATLANTIS: A full system model exploring marine ecosystem dynamics in a living marine resource management context. Progress in Oceanography 2010; 87:214-234.

[15] Chassot C, Bonhommeau S, Mélin F, Watson R, Gascuel D, Le Pape O. Global marine primary production constrains fisheries catches. Ecology letters 2010; 13: 495-505. 
[16] Blanchard J., Coll M., Trenkel V., Vergnon R., YemaneD., Jouffre D., Link J., Shin Y.S. Trend analysis of indicators: a comparison of recent changes in the status of marine ecosystems around the world, ICES Journal of Marine Science 2010; 67:732-744

[17] Thrush S, Dayton P. Disturbance to marine benthic habitats by trawling and dredging: implications for marine biodiversity. Annual Review of Ecology, Evolution and Systematics 2002; 33:449-473.

[18] Ulrich C, Le Gallic B, Dunn M, Gascuel D. A multi-species multi-fleet bioeconomic simulation model for the English Channel artisanal fisheries. Fisheries Research 2002; 58:379-401.

[19] Ulrich C, Andersen B, Sparre P, Nielsen R. TEMAS: fleet-based bioeconomic simulation software to evaluate management strategies accounting for fleet behaviour. ICES Journal of Marine Science 2007; 64:647-651.

[20] Hoff A, Frost H. Modelling economic response to harvest and effort control in the North Sea cod fishery. Aquatic Living Resources 2008, 21:265-273.

[21] Christensen V, Walters C. Trade-offs in ecosystem scale optimization of fisheries managament policies. Bulletin of Marine Science 2004; 74:549-562.

[22] Jennings S, Rice J. Towards an ecosystem approach to fisheries in Europe: a perspective on existing progress and future directions. Fish and Fisheries 2011; 12: 125-137

[23] Rice J. Managing fisheries well: delivering the promises of an ecosystem approach. Fish and Fisheries 2011; 12: $209-231$

[24] EC 2008, council regulation No 2371-2002 on the conservation and sustainable exploitation of fisheries resources under the Common Fisheries Policy

[25] ICES. Report of the ICES Advisory Committee. ICES, Copenhagen, Denmark. 2010, 95 pp.

[26] STECF, Casey J, Vanhee W, Doerner H, (eds). Scientific, Technical and Economic Committee for Fisheries. Review of Scientific advice for 2012 Part 2. Office for Official Publications of the European Communities, Luxembourg. EUR - Scientific and Technical Research series, ISSN 1018-5593. 2012, 257 pp.

[27] ICES. Report of the Working Group on the Ecosystem Effects of Fishing Activities, ICES, Copenhagen, Denmark. 2009

[28] Gascuel D, Döring R, Druon J-N, (Eds.). - Development of the Ecosystem Approach to Fisheries Management (EAFM) in European Seas. STECF/SGMOS-10-03 Working Group report, Office for Official Publications of the European Communities, Luxembourg. EUR - Scientific and Technical Research series, ISSN 1018-5593. 2010, 144 p.

[29] Pinnegar J, Jennings S, O'Brien C, Polunin N. Long-term catches in the trophic level of the Celtic Sea fish community and fish market price distribution. Journal of Applied Ecology 2002; 39:377-390.

[30] Guénette S, Gascuel D. Shifting baselines in European fisheries: the case of the Celtic Sea and Bay of Biscay. Submitted to Ocean and costal management.

[31] Froese R, Proelß A. Rebuilding fish stocks no later than 2015: will Europe meet the deadline? Fish and Fisheries 2010; 11:194-202.

[32] ICES. Report of the ICES Advisory Committee. ICES Advice, Copenhagen, Denmark . 2008, 267 pp.

[33] Garcia S, De Leiva Moreno J. Evolution of the state of fish stocks in the Northeast Atlantic within a precautionary framework, 1970-2003: a synoptic evaluation. ICES Journal of Marine Science 2005; 62:1603-1608.

[34] Pauly D, Christensen V, Dalsgaard J, Froese R, Torres F. Fishing Down Marine Food Webs. Science 1998; 279:860-863.

[35] Anderson J, Guillen J, (Ed). The 2010 Annual Economic Report on the European Fishing Fleet. JRC Scientific and Technical Report, STECF, Report EUR xxxxEN. 2010, 362 pp. 
[36] STECF, Casey J, Vanhee W, Doerner H, (eds). 34rh Plenary meeting of the Scientific, Technical and Economic Committee for Fisheries (PLEN-10-02), Jully 2010, Copenhaguen. Office for Official Publications of the European Communities, Luxembourg. EUR - Scientific and Technical Research series - ISSN 1018-5593. $176 \mathrm{p}$.

[37] Essington T, Beaudreau A, Wiedenmann J. Fishing through marine food webs. Proceedings of the National Academy of Sciences 2006; 103:3171-3175.

[38] Piet G, Rice J. Performance of precautionary reference points in providing management advice on North Sea fish stocks. ICES Journal of Marine Science 2004; 61: 1305-1312.

[39] European Commission. Commission Decision of 6 November 2008 adopting a multiannual Community programme pursuant to Council Regulation (EC) No 199/2008 establishing a Community framework for the collection, management and use of data in the fisheries sector and support for scientific advice regarding the common fisheries policy (2008/949/EC). Official Journal L 346 , 23/12/2008:0037

[40] Le Quesne W, Frid C, Paramor O, Piet G, Rogers S, Velasco F. Assessing the impact of fishing on the Marine Strategy Framework Directive objectives for Good Environmental Status. Developing and testing the process across selected RAC regions: the North Sea. 2010.

[41] ISO 14010 standard on Environmental Management System, EMS, concerning Life Cycle Assessment of products and processes. 2006.

[42] European Commission - Joint Research Centre, Institute for Environment and Sustainability: International Reference Life Cycle Data System (ILCD) Handbook - General guide for Life Cycle Assessment, 2010.

[43] Sabatella, E.; Nord, J.; Guillen, J et al. STECF Report on Quality aspects of the collection of economic data - methods of calculation of the indicators and sampling strategies (SGECA-09-022009) (2009)

[44] Heymans J, Mackinson S, Sumaila R, Dyck A, Little A. The Impact of Subsidies on the Ecological Sustainability and Future Profits from North Sea Fisheries. PLoS ONE 2011; 6(5): e20239.

[45] Mesnil B. Public-aided crises in the French fishing sector. Ocean \& Coastal Management 2008; 51:689-700.

[46] FAO The state of food and agriculture. Paying farmers for environmental services. Rome (Italie), 2007.

[47] K. Baylis, S. Peplow, G. Rausser, L, Simon. Ecological Economics 2008; 65: 753. 
Table 1: Area (ICES divisions and subdivisions; see Fig. 1), years of assessment and composition of the aggregation of stocks used for the stock synthesis

\begin{tabular}{|c|c|c|c|c|c|c|c|}
\hline \multicolumn{4}{|c|}{ Celtic Sea } & \multicolumn{4}{|c|}{ North Sea } \\
\hline $\mathrm{n}$ & Period & Species & Area & $\mathrm{n}$ & Period & Species & Area \\
\hline 4 & $\begin{array}{l}1972- \\
2008\end{array}$ & $\begin{array}{c}\text { Cod } \\
\text { Herring } \\
\text { Mackerel } \\
\text { Sole }\end{array}$ & $\begin{array}{l}\text { VIIe-k + 64\% VIIde } \\
\text { VIIe-k + 64\%VIIde } \\
\text { VIIe-k + 64\% VIIde } \\
\text { VIII-k + 64\% VIIde }\end{array}$ & 6 & $\begin{array}{l}1967- \\
2008\end{array}$ & $\begin{array}{c}\text { Cod } \\
\text { Haddock } \\
\text { Herring } \\
\text { Plaice } \\
\text { Saithe } \\
\text { Sole }\end{array}$ & $\begin{array}{l}\text { IV, VIId, IIIa } \\
\text { IV, IIIa } \\
\text { IV, VIId, IIIa } \\
\text { IV } \\
\text { IV, IIIa, VI } \\
\text { IV }\end{array}$ \\
\hline 5 & $\begin{array}{l}1978- \\
2008\end{array}$ & $\begin{array}{c}\text { Idem + } \\
\text { Hake }\end{array}$ & VIIe-k + 64\%VIIde & & & $\begin{array}{c}\text { Idem + } \\
\text { Mackerel }\end{array}$ & IV \\
\hline 9 & $\begin{array}{l}1982- \\
2008\end{array}$ & $\begin{array}{c}\text { Idem + } \\
\text { Horse } \\
\text { mackerel } \\
\text { Plaice } \\
\text { Whiting }\end{array}$ & $\begin{array}{c}\text { VIIe-k + 64\%VIIde } \\
\text { VIIe-k + } 64 \% \text { VIIde } \\
\text { VIIe-g } \\
\text { VIIe-k + 64\%VIIde }\end{array}$ & 14 & $\begin{array}{l}1984- \\
2007\end{array}$ & $\begin{array}{c}\text { Sandeel } \\
\text { Sole } \\
\text { Sole } \\
\text { Whiting } \\
\text { Plaice } \\
\text { Horse mack. } \\
\text { Norw. pout }\end{array}$ & $\begin{array}{c}\text { IV } \\
\text { VIId } \\
\text { IIIa } \\
\text { IV, VIId } \\
\text { VIId } \\
\text { IV } \\
\text { IV, IIIa }\end{array}$ \\
\hline
\end{tabular}


Table 2. Characteristics of the most representative fleets operating in the CS (a) and the North Sea (b) ; values landed by each fleet (in $\mathrm{M} €$ and in percentage of the total value landed in the ecosystem). Due to misreporting, French data in the CS are only available at the division level. (From the database of the UE annual economic report data call $[28,35])$

- $\mathbf{a}$ -

\begin{tabular}{|c|c|c|c|c|c|}
\hline Fleet code & Country & Gear/size $(m)$ & $\begin{array}{c}\text { Value in VIIe-k } \\
+ \text { French fleets in } \\
\text { VII (M€) }\end{array}$ & $\begin{array}{c}\% \text { of total } \\
\text { value (without } \\
\text { French fleets) }\end{array}$ & $\begin{array}{l}\begin{array}{c}\% \text { of total value } \\
\text { (including } \\
\text { French fleets) }\end{array} \\
\text { a }\end{array}$ \\
\hline BELTBB2440 & Belgium & Beam trawl (24-40) & 11.0 & $2.9 \%$ & $1.4 \%$ \\
\hline GBRDTS2440 & \multirow{3}{*}{ UK } & Demersal trawl (24-40) & 11.6 & $3.1 \%$ & $1.5 \%$ \\
\hline GBRFPO10 & & Pots and traps $(<10)$ & 11.2 & $3.0 \%$ & $1.5 \%$ \\
\hline GBRTBB2440 & & Beam trawl (24-40) & 19.8 & $5.2 \%$ & $2.6 \%$ \\
\hline IRLDTS1224 & \multirow{5}{*}{ Ireland } & Demersal trawl (12-24) & 48.3 & $12.8 \%$ & $6.3 \%$ \\
\hline IRLDTS2440 & & Demersal trawl (24-40) & 42.8 & $11.3 \%$ & $5.6 \%$ \\
\hline IRLPMP12 & & Polyvalent $(<12)$ & 20.8 & $5.5 \%$ & $2.7 \%$ \\
\hline IRLPTS40XX & & Pelagic trawl (>40) & 14.0 & $3.7 \%$ & $1.8 \%$ \\
\hline IRLTBB2440 & & Beam trawl (24-40) & 13.1 & $3.5 \%$ & $1.7 \%$ \\
\hline NDLTM40XX & Netherlands & Pelagic trawl $(>40)$ & 18.9 & $5.0 \%$ & $2.5 \%$ \\
\hline FRADTS1224 & \multirow{2}{*}{ France } & Demersal trawl (12-24) & 313.1 & & $41.0 \%$ \\
\hline FRADRB1224 & & Dredge (12-24) & 71.9 & & $9.4 \%$ \\
\hline \multicolumn{3}{|c|}{ Others } & 167.1 & $44.1 \%$ & $21.9 \%$ \\
\hline \multicolumn{3}{|c|}{ Total } & 763.7 & $100 \%$ & $100 \%$ \\
\hline
\end{tabular}

- b -

\begin{tabular}{|c|c|c|c|c|}
\hline Fleet code & Country & Gear/size(m) & Value (M€) & $\%$ of total value \\
\hline BELTBB24-40 & Belgium & Beam trawl (24-40) & 36.2 & $4 \%$ \\
\hline DNKTM24-40 & \multirow{2}{*}{ Denmark } & Pelagic trawl (24-40) & 37.4 & $4 \%$ \\
\hline DNKTM40XX & & Pelagic trawl $(>40)$ & 82.2 & $8 \%$ \\
\hline GBRDTS18-24 & \multirow{4}{*}{ UK } & Demersal trawl (18-24) & 89.1 & $9 \%$ \\
\hline GBRDTS24-40 & & Demersal trawl (24-40) & 82.4 & $8 \%$ \\
\hline GBRFPO10 & & Pots and traps $(<10)$ & 29.8 & $3 \%$ \\
\hline GBRPS40XX & & Purse seine $(>40)$ & 66.4 & $6 \%$ \\
\hline NLDTBB18-24 & \multirow{3}{*}{ Netherlands } & Beam trawl (18-24) & 58.8 & $6 \%$ \\
\hline NLDTBB40XX & & Beam trawl $(>40)$ & 113.9 & $11 \%$ \\
\hline NLDTM40XX & & Pelagic trawl $(>40)$ & 37.4 & $4 \%$ \\
\hline \multicolumn{3}{|c|}{ Others } & 397.9 & $39 \%$ \\
\hline \multicolumn{3}{|c|}{ Total } & 1031.4 & $100 \%$ \\
\hline
\end{tabular}




\section{Figure captions}

Fig 1. Map of the study areas: the North Sea (ICES subdivisions VIIefghjk) and the Celtic Sea (ICES subdivisions IIIa, IVabc and VIId)

Fig 2. Celtic Sea and North Sea landings and stock synthesis. Proportion of stocks assessed by ICES (a and $b$, dotted lines), and landings of the two most landed species, other assessed species and non-assessed species (upper a and b); landings of the stocks assessed by ICES excluding the two most landed species (lower a, b). Mean fishing mortality, spawning stock biomass and recruitment index (c, d); for the Celtic Sea, solid line refers to 4 assessed stocks, dotted line to 5 stocks and dashed line to 9 stocks (see Table 1). For the North Sea, solid line refers to 6 stocks and dotted to 14 stocks (see Table 1).

Fig 3. Current state of exploitation of stocks in the Celtic Sea and North Sea. Status of each of the assessed stocks ( $\mathrm{a}, \mathrm{b}$ top). Mean trajectory of the set of assessed stocks ( $\mathrm{a}, \mathrm{b}$ bottom) with two series of data (solid white refers 5 stocks in CS and to 6 stocks in the NS; dotted black to 2 stocks in CS and 9 stocks in the NS; see Table 1). Available landing-based ecosystem indicators (c, d): trophic level of landings for CS and NS (white circles), mean length of landings in the NS (black circles), mean maximum length in landings (white) and for demersal species (black) for the CS, and proportion of predators in landings for the NS.

Fig 4. Indicators of economic performances for the main fleet segments operating in the Celtic Sea (top and the North Sea (bottom) in 2008: gross value added, operating cash flow, profit/loss and direct subsidies (from AER 2010).

Fig 5. Impact (partial fishing mortalities derived from ICES assessments) of selected fleets on stocks assessed by ICES in CS and NS (a, b). Dependency of the selected fleet segments to the CS and NS stocks (c,d). Sustainability indices of selected fleets in CS and NS, according to the main assessed stocks exploited by each fleet (e, f; see text); $\mathrm{B}_{0.1}$ and $\mathrm{F}_{0.1}$ are management targets and $\mathrm{B}_{\mathrm{pa}}$ and $\mathrm{F}_{\mathrm{pa}}$ are the precautionary limits to biomass and fishing mortality (from ICES assessments). See table $2 \mathrm{a}$ and $2 \mathrm{~b}$ for fleets identification codes, nationality, fishing gear and size.

Fig 6. Fleets economic dependency on CS and NS compared to their impact on ecosystems. 


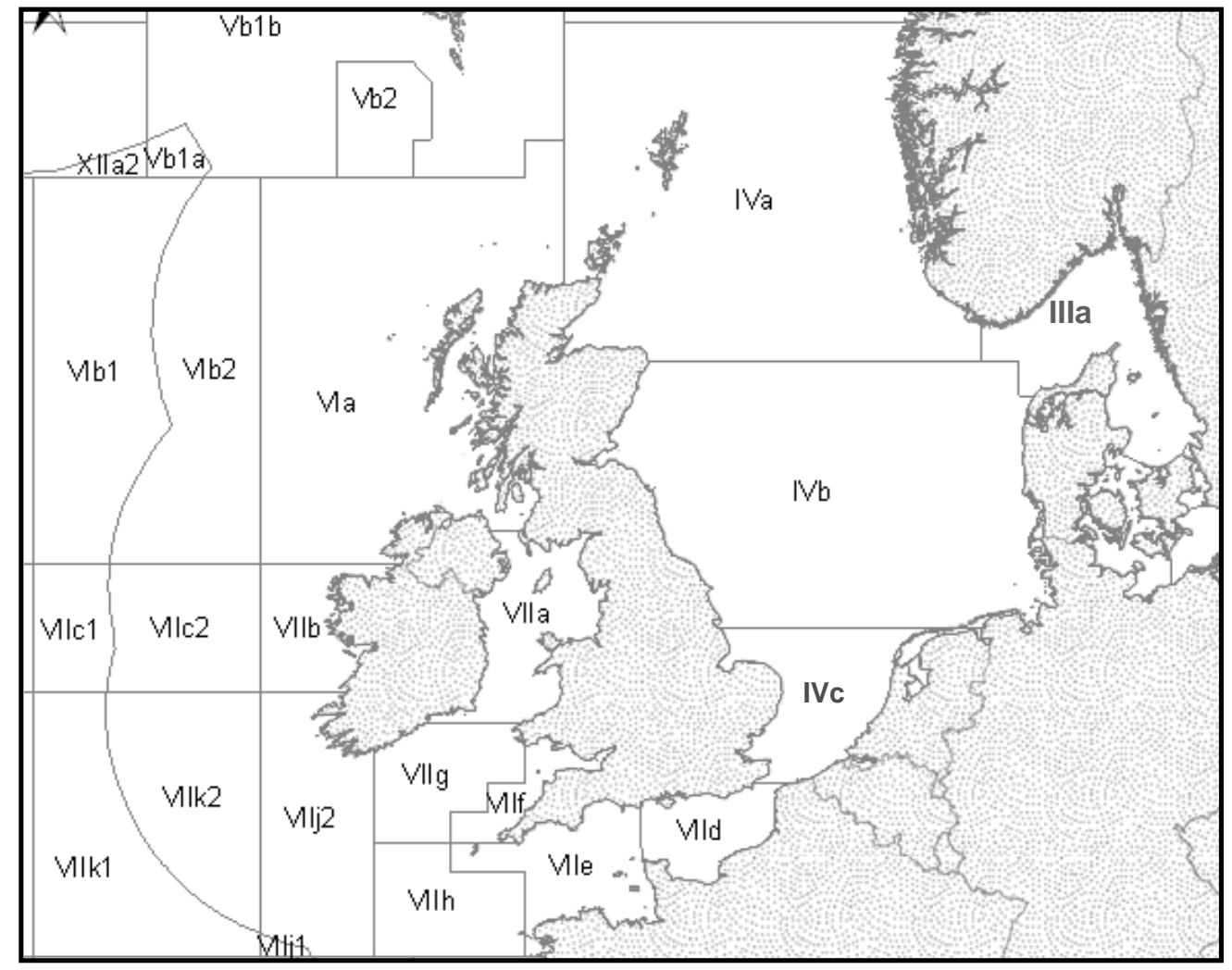

Fig 1. Map of the study areas: the North Sea (ICES subdivisions VIIefghjk) and the Celtic Sea (ICES subdivisions IIIa, IVabc and VIId) 


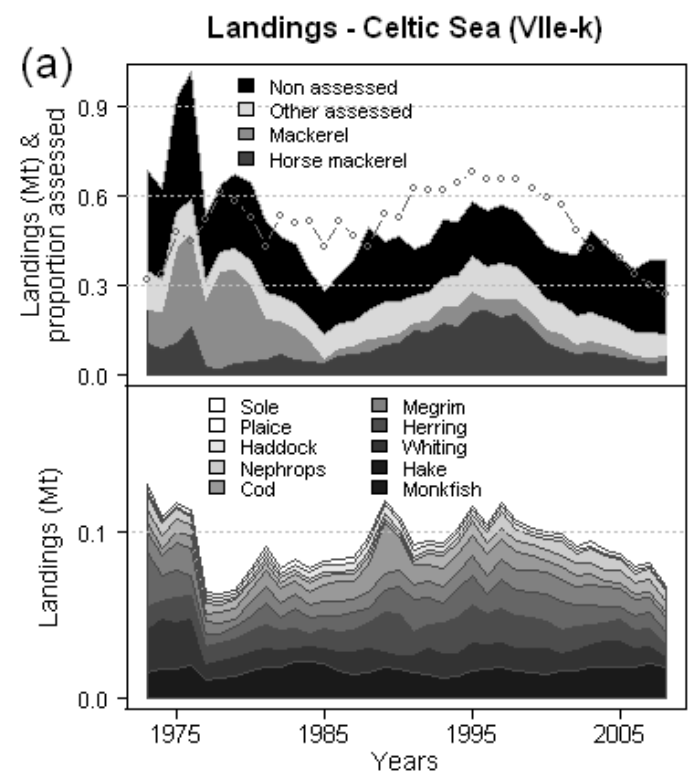

(b) Landings - North Sea (IVa-c)

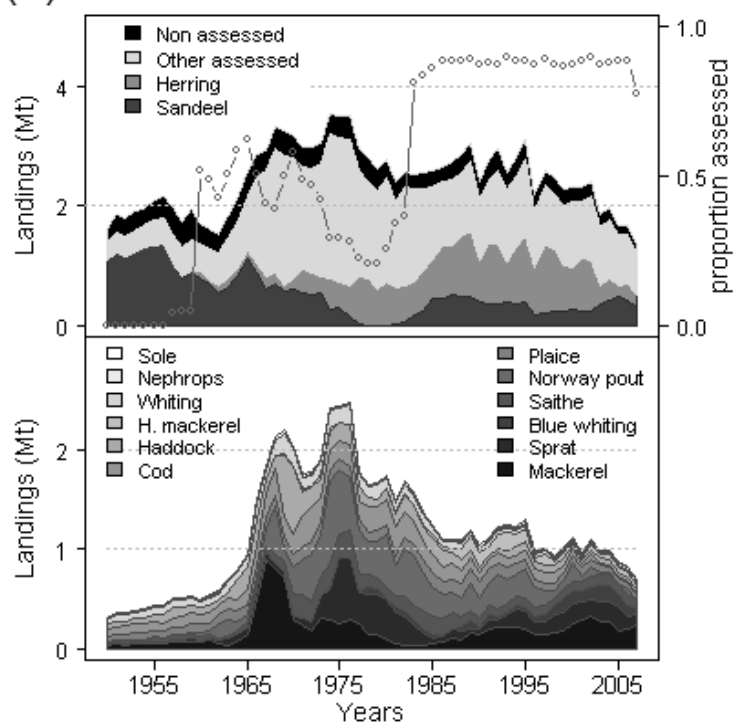

(c) Stock synthesis - Celtic Sea (VIle-k)

(d) Stock synthesis - North Sea (IVa-c)
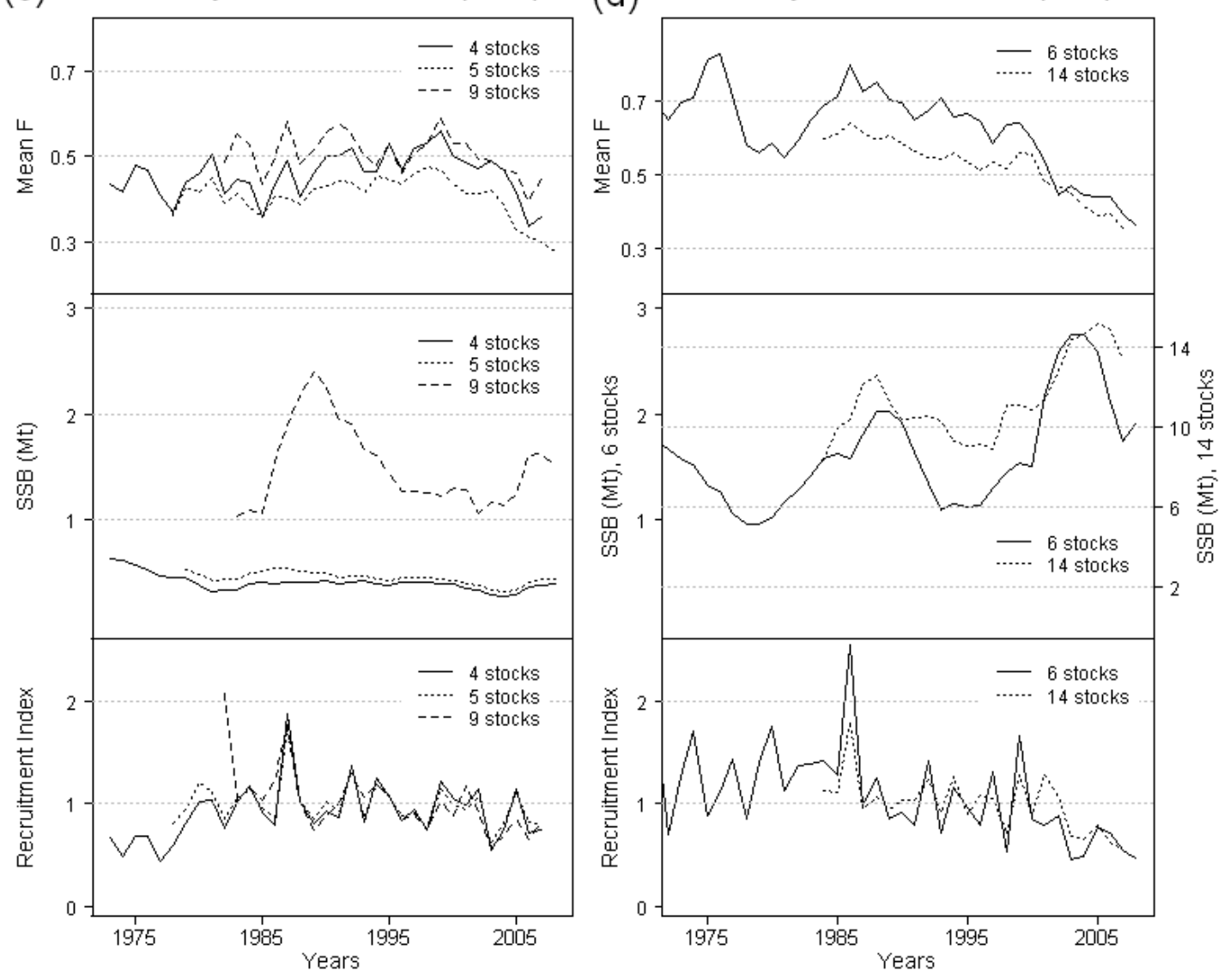

Fig 2. Celtic Sea and North Sea landings and stock synthesis. Proportion of stocks assessed by ICES (a and $b$, dotted lines), and landings of the two most landed species, other assessed species and non-assessed species (upper a and b); landings of the stocks assessed by ICES excluding the two most landed species (lower a, b). Mean fishing mortality, spawning stock biomass and 
recruitment index (c, d); for the Celtic Sea, solid line refers to 4 assessed stocks, dotted line to 5 stocks and dashed line to 9 stocks (see Table 1). For the North Sea, solid line refers to 6 stocks and dotted to 14 stocks (see Table 1). 
(a)
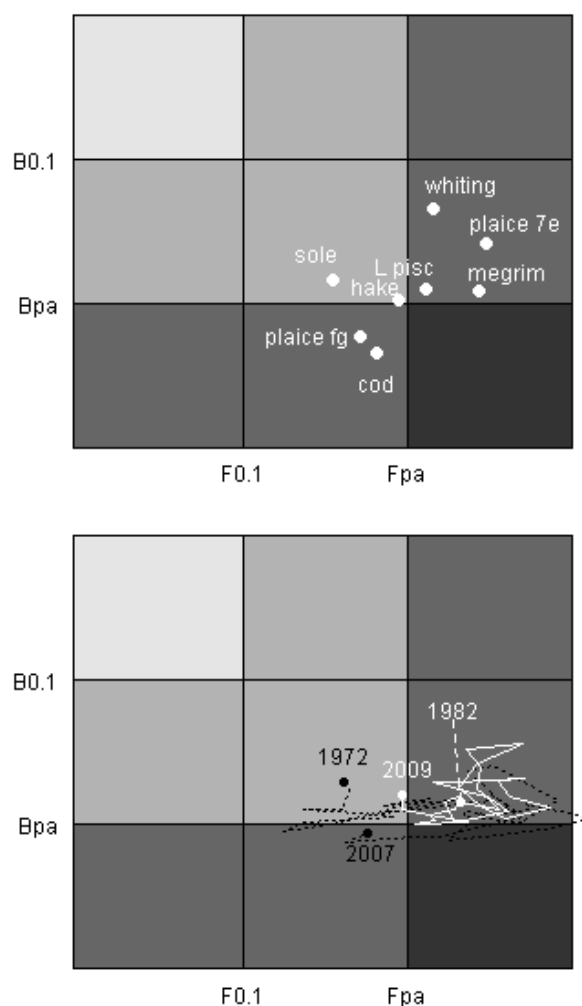

(c) Ecosystem Indicators - Celtic Sea

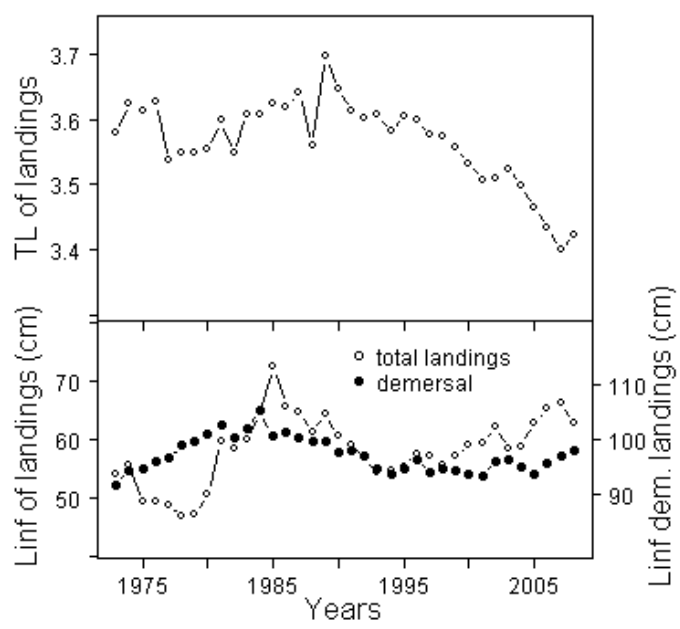

(b)

North Sea Diagnostic
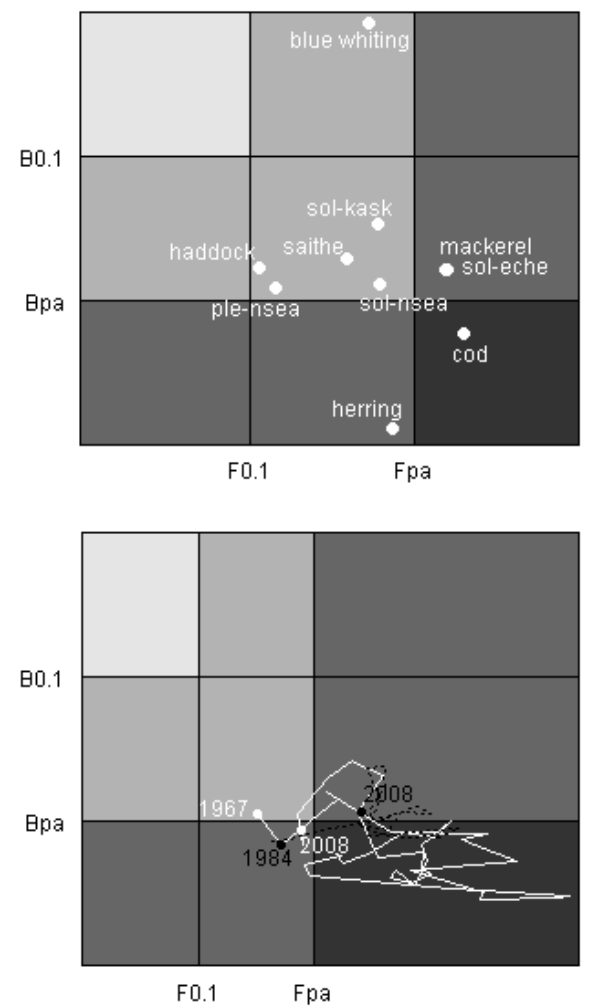

(d) Ecosystem Indicators - North Sea

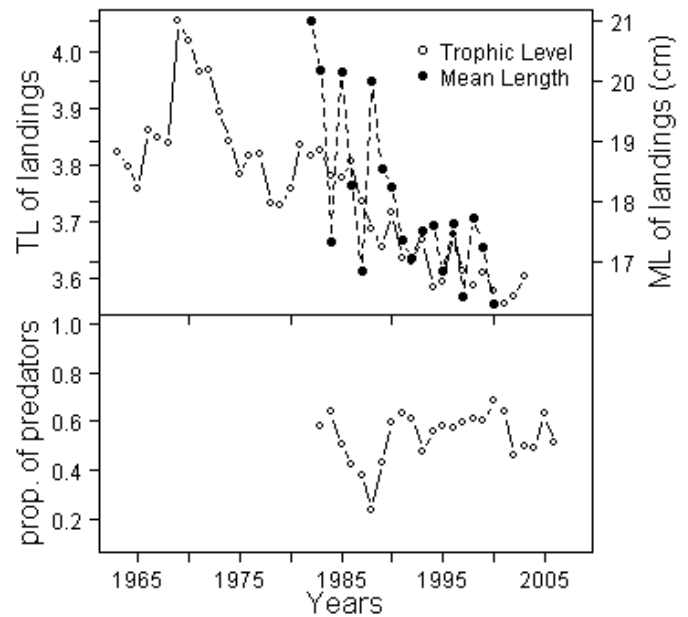

Fig 3. Current state of exploitation of stocks in the Celtic Sea and North Sea. Status of each of the assessed stocks ( $\mathrm{a}, \mathrm{b}$ top). Mean trajectory of the set of assessed stocks ( $\mathrm{a}, \mathrm{b}$ bottom) with two series of data (solid white refers 5 stocks in CS and to 6 stocks in the NS; dotted black to 2 stocks in CS and 9 stocks in the NS; see Table 1). Available landing-based ecosystem indicators (c, d): trophic level of landings for CS and NS (white circles), mean length of landings in the NS (black circles), mean maximum length in landings (white) and for demersal species (black) for the CS, and proportion of predators in landings for the NS. 


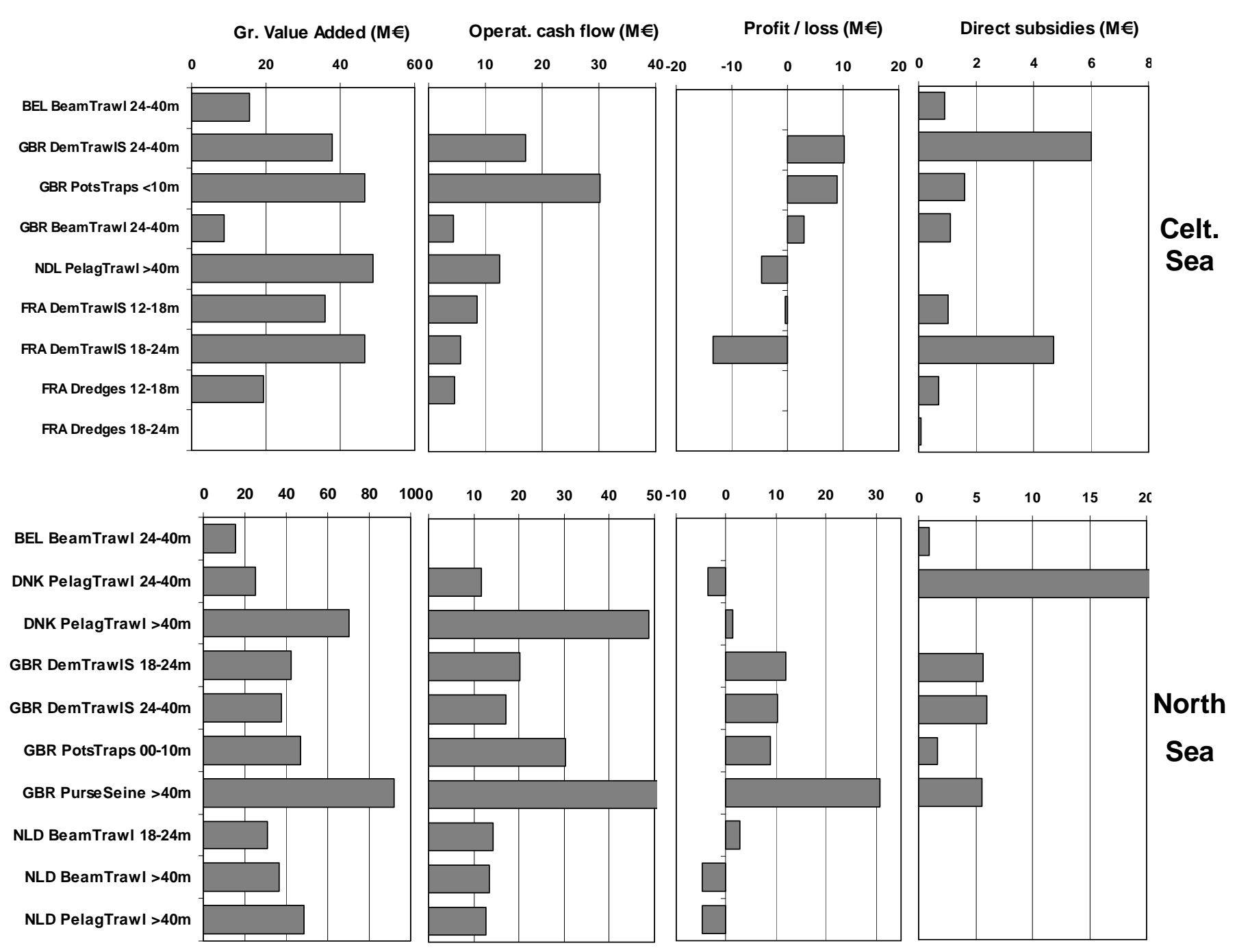

Fig 4. Indicators of economic performances for the main fleet segments operating in the Celtic Sea (top and the North Sea (bottom) in 2008: gross value added, operating cash flow, profit/loss and direct subsidies (from AER 2010). 
(a)

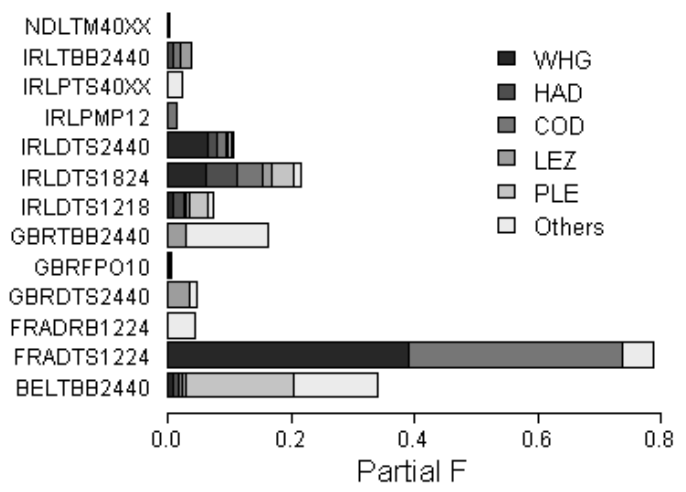

(C) Economic dependency on CS stocks

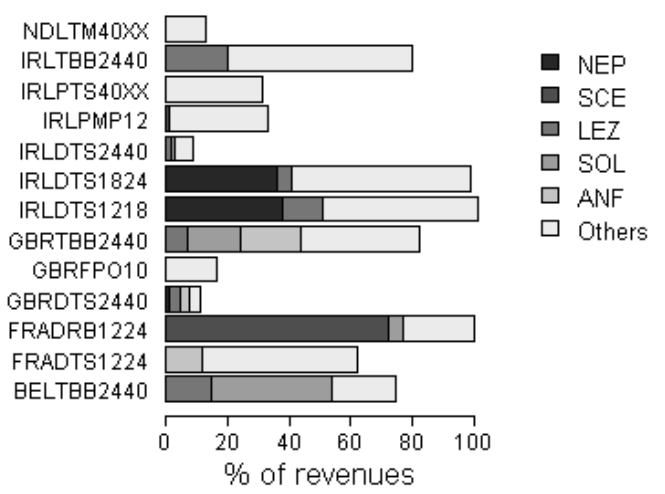

(e) Celtic Sea fleets sustainability

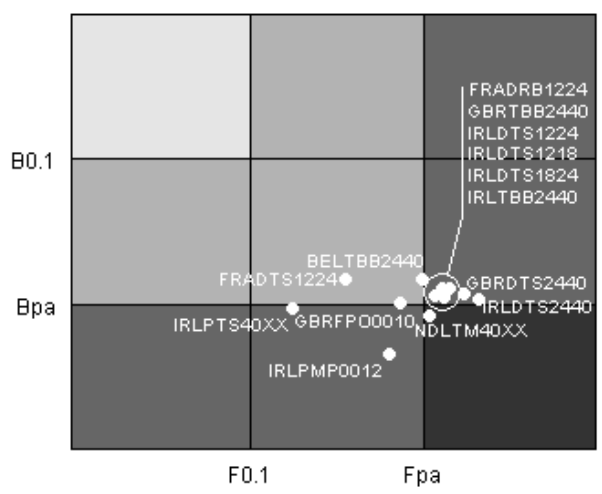

(b) Fleet impact on NS stocks

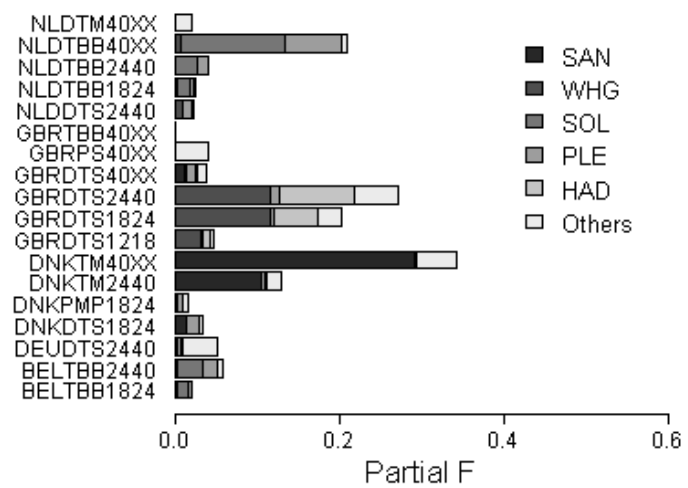

(d) Economic dependency on NS stocks

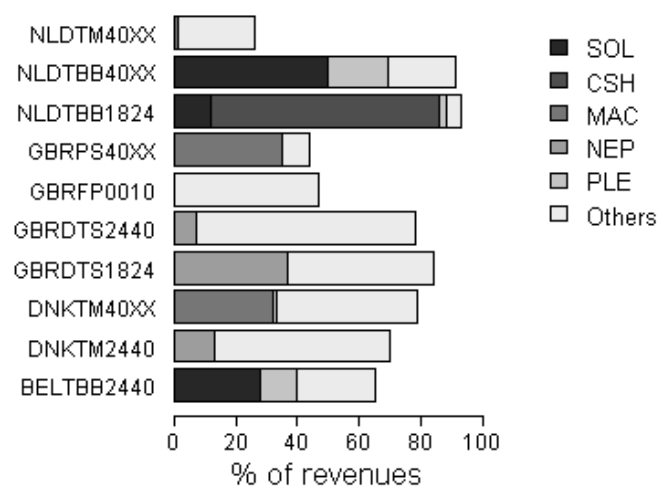

(f) North Sea fleets sustainability

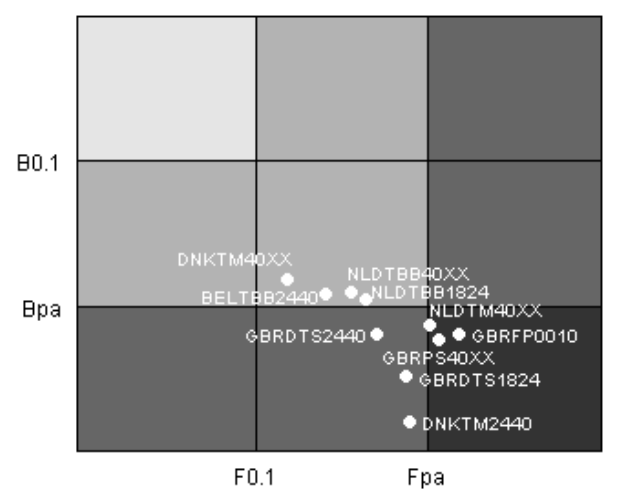

Fig 5. Impact (partial fishing mortalities derived from ICES assessments) of selected fleets on stocks assessed by ICES in CS and NS (a, b). Dependency of the selected fleet segments to the CS and NS stocks (c,d). Sustainability indices of selected fleets in CS and NS, according to the main assessed stocks exploited by each fleet (e, f; see text); $\mathrm{B}_{0.1}$ and $\mathrm{F}_{0.1}$ are management targets and $\mathrm{B}_{\mathrm{pa}}$ and $\mathrm{F}_{\mathrm{pa}}$ are the precautionary limits to biomass and fishing mortality (from ICES assessments). See table $2 \mathrm{a}$ and $2 \mathrm{~b}$ for fleets identification codes, nationality, fishing gear and size. 

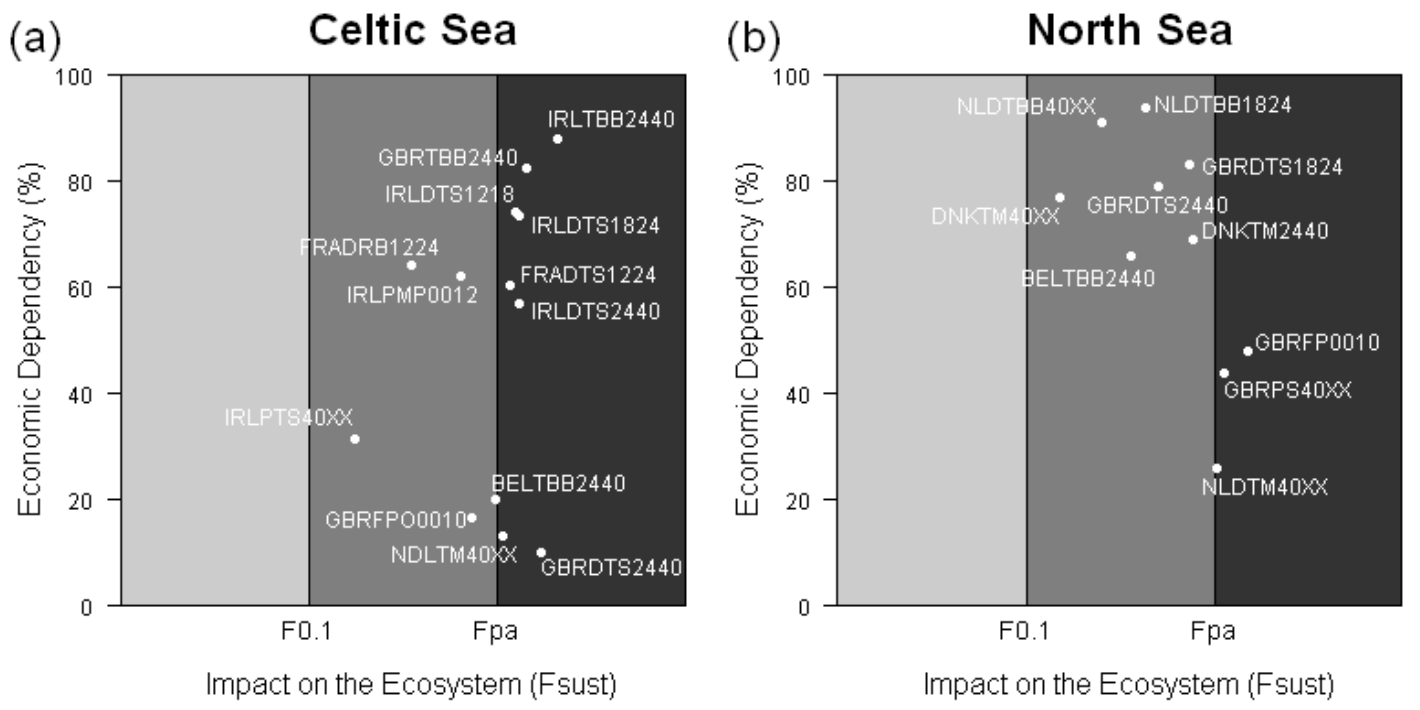

Fig 6. Fleets economic dependency on CS and NS compared to their impact on ecosystems. 